\title{
Delayed central cord syndrome after a handstand in a child: Case report
}

\author{
KS Lee, JW Doh, HG Bae and IG Yun \\ Department of Neurosurgery, Soonchunhyang University Chonan Hospital, Chonan 330-100, Korea
}

\begin{abstract}
We report a case of a central cord syndrome in a 7 year-old girl. After several handstands, with sudden upper thoracic back pain and weakness of the legs 2 to $3 \mathrm{~h}$ later, then rapidly progressive tetraplegia with apnea. Plain X-rays and CT myelography of the cervical spine revealed no abnormalities. Although the initial neurological deficit was severe enough to require the child to be placed on a mechanical ventilator, she recovered to be able to walk on the 24th hospital day. Since the development of a central cord syndrome after handstands is exceptional in a child with a normal cervical spine, we report here briefly.
\end{abstract}

Keywords: central cord syndrome; spinal cord injury with radiographic abnormality; children; handstand

\section{Introduction}

The majority of instances of central cord syndrome (CCS) occur in the elderly, with arthritic changes in the spine. ${ }^{1}$ The reported incidence of pediatric spinal cord injuries among all spinal cord injuries is one to $10 \% .^{2-4}$ Although spinal cord injury without radiographic abnormality (SCIWORA) is relatively common in young children (birth -8 years), the incidence of SCIWORA has been estimated as $10-20 \%$ of all pediatric spinal trauma. ${ }^{5}$ The CCS accounted for $41.7 \%$ of pediatric SCIWORA. ${ }^{6}$ Thus, pediatric CCS without radiographic abnormality accounts for less than $1 \%$ of all spinal cord injuries. Spinal cord injuries in children usually result from significant trauma. ${ }^{2,4,6}$ CCS after trivial trauma is so rare that only eight cases have been reported. ${ }^{4-7-10}$ We recently experienced such an example in a 7-year-old girl.

\section{Case report}

This 7-year-old girl was admitted via the emergency room because of sudden respiratory difficulty. At times she liked to stand on her head. On the day of admission, she stood on her head several times without falling. Two to three hours later, she complained of sudden upper thoracic back pain and weakness of the legs, and then vomited. There was no history of trauma except for standing on her head. On the way to the Hospital, she vomited again, and had severe dyspnea.

On arrival, she was cyanotic and apneic. Immediate resuscitation including intubation and ventilation resulted in recovery of consciousness, and she could

Correspondence: K Seok Lee open her eyes, but was apneic and tetraplegic. Physical examination revealed no external evidence of trauma. The deep tendon reflexes were hyperactive in the lower extremities, but hypoactive in the upper extremities. Muscle tone was increased in the legs, but decreased in the arms. The plantar response was extensor on the left and equivocal on the right. Plain cervical radiographs and computed tomographic scans of the cervical spine and the brain with intrathecal contrast enhancement (CT myelography) showed no abnormal findings. Spinal fluid pressure was $110 \mathrm{~mm}$ of CSF; and the fluid was clear without any cells. Glucose concentration was $107 \mathrm{mg} \%$ and protein concentration was $46 \mathrm{mg} \%$. She remained on a ventilator.

She remained apneic for 2 weeks, but could move her legs progressively from the second hospital day (HD). Motor functions of the upper extremities remained plegic. From the 8th HD, she could move her fingers. Weaning off the ventilator was possible on the 13th HD and she was extubated on the 15th HD. Motor power improved day by day, she could walk on the 24th HD, and was discharged from hospital on the 28th HD.

She could go to school without help about 2 months after discharge home. Bladder function was normal. She could extend her elbows, abduct the shoulders up to $45^{\circ}$, and move her fingers. Was unable to flex her elbows. Motor weakness was slightly more severe on the right side. Although there was steady improvement the neurological deficits were almost fixed from 6 months until one and half years after discharge.

\section{Discussion}

The anatomical and biomechanical characteristics of the pediatric cervical spine that make a young child 
susceptible to SCIWORA are well documented. ${ }^{3,4,6}$ These include hypermobility of the spine related to ligamentous laxity, open ossification centers, a more horizontal orientation of the articular facet joints, immature joints of Luschka, a wedge shape of the vertebral bodies and a relatively larger head with underdeveloped neck musculature. However, spinal cord injuries in children usually result from significant trauma, most often motor-vehicle accidents or a fall. $^{2,4,6}$ CCS after trivial trauma is so rare that only eight cases have been reported (Table 1)..$^{4,7-10}$ Six were female, aged $1-3$ years. The smaller size of the cervical spinal canal in girls may account for the female predominance. ${ }^{3,4}$

A fall from a relatively low height was the cause in six cases. Somersaults, 'jumping on a bed', and a handstand caused spinal cord injury in the other three cases. Failure in a somersault is a common cause of spinal injury in gymnastics. ${ }^{11,12}$ Spinal injury from a handstand is extremely rare. Vlcek and Ito ${ }^{13}$ reported a patient with tetraparesis with an Arnold-Chiari type I malformation, who slipped whilst performing a handstand on a sofa. Riviello et al. ${ }^{4}$ listed eight cases of delayed CCS after trivial trauma, including this one of tetraparesis. We excluded this case, because the legs were weaker than the arms. CCS is characterized by disproportionately more motor impairment of the upper than of the lower extremities. ${ }^{1}, 14$

So-called 'trivial trauma' needs to be defined. In fact, spinal cord injury is not a trivial injury. When can we designate a trauma as being 'trivial'? Erlich et $a l .{ }^{15}$ reported a case of Bell's cruciate paralysis after a person 'rolled off a low bed', who had an ArnoldChiari type I anomaly. Computed tomographic scan revealed a fracture of the lateral mass of the atlas despite the seemingly trivial nature of the trauma. Cheshire $^{8}$ reported a case of CCS after someone 'tripped and fell'. Although this event seemed to be trivial, his neck was extremely hyperflexed and he immediately went limp. A fracture of the immature spine is difficult to detect on routine radiographs. ${ }^{5,16}$ Absence of a fracture on radiographs is not an index of trivial trauma. Along with the radiographic evaluation, we should consider not only the dynamic forces but also static deformability as in Cheshire's ${ }^{8}$ case. It is appropriate to describe the specific type of trauma instead of ill-defined terms of 'trivial' trauma.

The pathophysiology of CCS includes a primary neuronal or vascular injury or a secondary impairment of spinal cord blood flow. ${ }^{4}$ Quencer et al. ${ }^{17}$ reported that the primary finding of CCS was diffuse disruption of axons in the lateral columns of the cervical cord instead of hemorrhage, necrosis or contusion within the central portion of the spinal cord. They suggested that the most common mechanism of injury in CCS might be direct compression of the spinal cord. Grabb and Pang $^{18}$ reported that self-reducing transient subluxation or distraction of the juvenile spine was responsible for the neurological injury and compressive lesions were rare in SCIWORA. However, direct compression cannot explain the delayed onset of neurological deficits in CCS after trivial trauma. The onset of neurological signs was delayed from a few minutes to several days in all of the reported cases of CCS after trivial trauma. A delay in the onset of neurological deficits or a delayed neurological deterioration is not rare, especially in pediatric SCIWORA. Dickman et al. ${ }^{5}$ reported that 30 of 201 reported cases of SCIWORA $(14.9 \%)$ had a delay in the onset of the deficits. The postulated mechanisms for delayed neurological deficits are vascular injury with progressive thrombosis, ${ }^{4,6,7}$ repeated subluxation in the presence of ligamentous injury or laxity, ${ }^{4,6}$ and longitudinal distraction and ischemia. ${ }^{19}$ Grabb and Pang $^{18}$ reported that ligament and disc injuries are highly correlated with the mechanism of injury, but not with the development of late instability. We feel that the most probable mechanism for delayed neurological deficits is a vascular injury with progressive thrombosis.

Although the onset of neurological deficits was delayed, progression was rapid once they began. ${ }^{9}$ Surgery may be beneficial in a few cases, ${ }^{20-22}$ but conservative treatment with proper immobilization is usually sufficient. The outcome of CCS in general is good $^{2,3}$ especially in childhood. ${ }^{2,24,25}$ Grabb and Pang $^{18}$ reported that the magnetic resonance imaging (MRI) findings of the cord were highly correlated with

Table 1 Summary of central cord syndrome after trivial trauma in children

\begin{tabular}{|c|c|c|c|c|c|c|}
\hline Case & Authors & Year & Sex/Age & Type of trauma & Onset & Outcome (FP) \\
\hline 1 & Ahman, et al & 1975 & $\mathrm{~F} / 4$ years & fell from swing & several hou & death (48 days) \\
\hline 2 & Ahman, et al & 1975 & $\mathrm{M} / 22$ months & fell to floor & $4 \mathrm{~h}$ & death ( 6 months) \\
\hline 3 & Cheshire & 1977 & $\mathrm{M} / 26$ months & fell backward & overnight & limited ambulation (18 months) \\
\hline 4 & Chen, Blaw & 1986 & $\mathrm{~F} / 2$ years & fell from crib & $1 \mathrm{~h}$ & normal (3 months) \\
\hline 5 & Chen, Blaw & 1986 & $\mathrm{~F} / 7$ years & jumped on bed & overnight & weak UE (6 months) \\
\hline 6 & Riviello, et al & 1990 & $\mathrm{~F} / 3$ years & somersault/fell & $30 \mathrm{~min}$ & spastic gait (2 years) \\
\hline 7 & Riviello, et al & 1990 & $\mathrm{~F} / 2$ years & fell from sofa & $2 \mathrm{~h}$ & mild quadriparesis ( 2 years) \\
\hline 8 & Bondurant, Oro & 1993 & $\mathrm{M} / 27$ months & fell from porch & $5 \min$ & weak UE (30 months) \\
\hline 9 & Lee, et al & 1995 & $\mathrm{~F} / 6$ years & handstand & $2-3 h$ & weak UE (18 months) \\
\hline
\end{tabular}

$\mathrm{FP}=$ follow up period; $\mathrm{UE}=$ upper extremities 
the prognosis of SCIWORA; poor with MRI evidence of major cord hemorrhage or cord discontinuity, good with MRI evidence of edema with or without minor cord hemorrhage, and complete recovery with normal MRI findings.

Spinal cord injury from trivial trauma is rare, but SCIWORA is relatively common in young children. Rapid progression of neurological deficits with apnea requires prompt diagnosis and appropriate urgent respiratory management.

\section{References}

1 Maroon JC, Abla AA, Wilberger JL, Bailes JE, Sternau LL. Central cord syndrome. Clin Neurosurg 1991; 37: 612-621.

2 Hadley MN, Zabramski JM, Browner CM, Rekate H, Sonntag VKH. Pediatric spinal trauma: review of 122 cases of spinal cord and vertebral column injuries. J Neurosurg 1988; 68: $18-24$.

3 Ruge JR, Simson GP, McLone DG, Cerullo LJ. Pediatric spinal injury: The very young. J Neurosurg 1988; 68: $25-30$.

4 Riviello JJ, Mark HG, Faerber EN, Steg NL. Delayed cervical central cord syndrome after trivial trauma. Ped Emer Care 1990; 6: $113-117$.

5 Dickman CA, Zabramski JM, Hadley MN, Rekate HL, Sonntag VKH. Pediatric spinal cord injury without radiographic abnormalities: report of 26 cases and review of the literature. $J$ Spinal Disord 1991; 4: 296-305.

6 Pang D, Wilberger JE. Spinal cord injury without radiographic abnormalities in children. J Neurosurg 1982; 57: 114-129.

7 Ahmann PA, Smith SA, Schwartz JF, Clark DB. Spinal cord infarction due to minor trauma in children. Neurology 1975; 25: $301-307$

8 Cheshire DJE. The paediatric syndrome of traumatic myelopathy without demonstrable vertebral injury. Paraplegia 1977; 15: $74-$ 85.

9 Chen LS, Blaw ME. Acute central cervical cord syndrome caused by minor trauma. J Pediatr 1986; 108: $96-97$.

10 Bondurant CP, Oro JJ. Spinal cord injury without radiographic abnormality and Chiari malformation. J Neurosurg 1993; 79: $833-838$.

11 Noguchi T. A survey of spinal cord injuries resulting from sports. Paraplegia 1994; 32: $170-173$.
12 Bailes JE, Hadley MN, Quigley MR, Sonntag VKH, Cerullo LJ. Management of athletic injuries of the cervical spine and spinal cord. Neurosurgery 1991; 29: 491-497.

13 Vlcek BW, Ito B. Acute paraparesis secondary to Arnold-Chiari type I malformation and neck hyperflexion. Ann Neurol 1987; 21: $100-101$.

14 Schneider RC, Cherry G, Pantek H. The syndrome of acute central cervical spinal cord injury. J Neurosurg 1954; 11: $546-$ 577.

15 Erlich V, Snow R, Heiere L. Confirmation by magnetic resonance imaging of Bell's cruciate paralysis in a young child with Chiari type I malformation and minor head trauma. Neurosurgery 1989; 25: $102-105$.

$16 \mathrm{O}^{\prime}$ Neal ML, Lord MJ, Ganey TM, Ogden JA. Spontaneously occurring fractures of the spine in skeletally immature animals. Spine 1994; 19: 1230 - 1236.

17 Quencer RM, Bunge RP, Egnor M, Green BA, Puckett W, Naidich TP, Post MJD. Acute traumatic central cord syndrome: MRI-pathological correlations. Neuroradiology 1992; 17: 234 237.

$18 \mathrm{Grabb}$ PA, Pang D. Magnetic resonance imaging in the evaluation of spinal cord injury without radiographic abnormality in children. Neurosurgery 1994; 35: 406-414.

19 Choi JU, Hoffman HJ, Hendrick EB, Humphreys RP, Keith WS. Traumatic infarction of the spinal cord in children. $J$ Neurosurg 1986; 65: $608-610$.

20 Brodkey JS, Miller CF, Harmody RM. The syndrome of acute central cervical spinal cord injury revisited. Surg Neurol 1980; 14: $251-257$.

21 Bose B, Northrup B, Osterholm J, Cotler JM, DiTunno JF. Reanalysis of central cervical cord injury management. Neurosurgery 1984; 15: $367 \quad 372$.

22 Fox JL, Wener L, Drennan DC, Manz HJ, Won DJ, Al-Mefty O. Central spinal cord injury: Magnetic resonance imaging confirmation and operative considerations. Neurosurgery 1988; 22: $340-347$.

23 Merriam WF, Taylor TK, Ruff SJ, McPhail MJ. A reappraisal of acute traumatic central cord syndrome. J Bone Joint Surg 1986; 68: $708-713$.

24 Penrod LE, Hede SK, Ditunno FJ Jr. Age effect on prognosis for functional recovery in acute traumatic central cord syndrome. Arch Phys Med Rehabil 1990; 71: 963-968.

25 Roth EJ, Lawler MH, Yarkony GM. Traumatic central cord syndrome: clinical features and functional outcomes. Phys Med Rahabil 1990; 71: 18-23. 